\title{
A PROTEÇÃO INTERNACIONAL DOS DIREITOS POLÍTICO-ELEITORAIS DAS MULHERES: ANÁLISE DOS CASOS "MARÍA MERCIADRI DE MORONI VS. ARGENTINA" E "JANET ESPINOZA E OUTRAS VS. PERU”
}

\author{
The international protection of women's political-electoral rights: analysis of \\ the cases "María Merciadri de Moroni vs. Argentina" and "Tanet Espinoza \\ and others vs. Peru"
}

\section{Pedro Henrique Costa de Oliveira}

Resumo: O presente estudo pretende analisar a importância da igualdade de participação política feminina no exercício do poder político, sob a ótica do Direito Internacional dos Direitos Humanos. Para tanto, parte da afirmação de que os direitos políticos das mulheres integram a categoria dos direitos humanos, uma vez que estes se encontram positivados em diversos tratados internacionais. Tal condição possibilita que a proteção dos direitos políticos das mulheres não se limite ao âmbito interno de cada Estado, mas também se dê por meio do sistema internacional de proteção dos direitos humanos. Por fim, analisar-se-ão dois casos de violação aos direitos políticos das mulheres levados ao conhecimento da Comissão Interamericana de Direitos Humanos. Trata-se de uma pesquisa de abordagem qualitativa, tendo como procedimento o levantamento bibliográfico e documental, com consulta à jurisprudência, sendo o texto estruturado em quatro seções. Após a introdução, faz-se uma discussão sobre o enquadramento dos direitos políticos como direitos humanos. Os direitos políticos das mulheres são objetos de análise da terceira seção. A última seção traz as considerações finais do texto.

Palavras-chave: Direitos políticos das mulheres. Sistema Internacional de Proteção dos Direitos Humanos. Tratados internacionais de direitos humanos. Comissão Interamericana de Direitos Humanos. Igualdade de gênero.

\begin{abstract}
The present study intends to analyze the importance of the equality of female political participation in the exercise of political power, from the point of view of International Human Rights Law. To that end, it is based on the assertion that women's political rights are in the category of human rights, since these rights are found in several international treaties. Such a condition makes it possible for the protection of women's political rights not only to be limited to the internal scope of each State but also through the international system of protection of human rights. Finally, two cases of violation of the political rights of women brought to the attention of the Inter-American Commission on Human Rights will be analyzed. It is a qualitative research, having as a procedure the bibliographical and documentary survey, with consultation to the jurisprudence, being the text structured in four sections. After the introduction, there is a discussion about the framing of political rights as human rights. Women's political rights are objects of analysis in the third section. The last section brings the final considerations of the text.
\end{abstract}

Keywords: Women's political rights. International System for the Protection of Human Rights. International human rights treaties. Inter-American Commission on Human Rights. Gender equality.

Artigo recebido em 26 jun. 2019 e aprovado em 2 ago. 2019. 


\section{Introdução}

O Direito Eleitoral tem reconhecida importância na efetivação e na garantia dos direitos políticos, os quais se encontram positivados em quase todos os principais diplomas internacionais, a evidenciar o seu reconhecimento como categoria abarcada pela força expansiva da proteção internacional dos direitos humanos.

Nesse diapasão, "vícios no processo eleitoral que afetem o livre exercício dos direitos políticos e a manutenção do regime democrático são tidos na conta de violações a direitos humanos, ficando, assim, sujeitos ao sistema internacional de proteção desses direitos” (MONTEIRO, 2015, p. 173).

Desta forma, qualquer ato praticado pelo Estado - não apenas oriundo do Poder Executivo, mas também do Legislativo e do Judiciário - que violem direitos políticos não podem ficar adstritos ao ordenamento doméstico, dado que o reconhecimento dessa categoria de direitos como direitos humanos - os quais possuem caráter universal - impede que sua proteção seja considerada como de responsabilidade exclusiva de um Estado.

A utilização do sistema internacional de proteção dos direitos humanos não exclui a utilização e o aprimoramento dos sistemas internos de cada Estado-Nação. Sistemas nacionais e internacionais devem ser um o complemento do outro; devem caminhar juntos, com a finalidade de alcançar o pleno respeito dos direitos humanos, fortalecendo-os.

Em matéria de direitos políticos, a Corte Interamericana de Direitos Humanos (Corte IDH) assentou que a obrigação dos Estados em respeitá-los não se cumpre com a simples emissão de uma norma que reconheça formalmente tais direitos, mas requer que o Estado adote as medidas necessárias para garantir seu pleno exercício, considerando a situação de debilidade ou desamparo em que se encontram os integrantes de certos setores ou grupos sociais, sendo indispensável que o Estado gere as condições e os mecanismos ótimos para que os direitos políticos possam ser exercidos de forma efetiva, respeitando o princípio de igualdade e não discriminação ${ }^{1}$.

É insofismável que as mulheres integrem tais grupos, vez que, não raro, veem seus direitos políticos admoestados, fundamentando o estado de sub-representação feminina no exercício do poder político.

${ }^{1}$ Corte IDH. Caso Yatama vs. Nicarágua. Exceções Preliminares, Mérito, Reparações e Custas. Sentença de 23 de junho de 2005, parágrafos 195 e 201. 
A IV Conferência Mundial das Nações Unidas sobre a Mulher, realizada no ano de 1995, em Pequim, representou um marco na reafirmação de que os direitos das mulheres são direitos humanos e que a igualdade de gênero - inclusive na esfera política - é uma questão de interesse universal. A partir de então, observa-se uma expansão ininterrupta da política de cotas em todos os continentes.

As cotas para as mulheres - políticas que determinam que certa proporção de mulheres seja incluída nas instituições - são um dos principais desenvolvimentos sócio-políticos dos últimos 30 anos. Na década de 1970, a regulamentação de cotas de representação legislativa das mulheres existia em poucos países. Hoje, as cotas eleitorais existem em mais de 130 países, em todas as regiões do mundo (KROOK; HUGHES; PAXTON, 2017, p. 332).

Este trabalho, portanto, destaca a contribuição do Direito Internacional dos Direitos Humanos para a construção da igualdade gênero na política, a partir da análise de vários diplomas internacionais ratificados pelo Brasil, bem como de casos levados à apreciação da Comissão Interamericana de Direitos Humanos (CIDH).

Assim, neste ensaio, apresenta-se a discussão dos direitos políticos como direitos humanos, para, após, tratar dos direitos políticos das mulheres no âmbito dos tratados internacionais, analisando, inclusive, casos de responsabilização (ou em vias de responsabilização) internacional de Estados que violaram tais direitos.

\section{Os direitos políticos como direitos humanos}

Insta, precipuamente, salientar que os direitos políticos foram positivados no Texto Constitucional de 1988, no Título II, em que repousam os direitos e as garantias fundamentais. Por conseguinte, o legislador constituinte, ao verificar a importância do gozo desses direitos para a fruição dos demais direitos, pois sua ausência retiraria da sociedade a possibilidade de participação na construção de decisões políticas, reconheceu a fundamentalidade dos direitos políticos, "não apenas pela topografia expressa na Carta, mas pelo conteúdo que encetam em face da opção do Constituinte de adoção de um regime democrático" (FERREIRA, 2015, p. 41). Tais direitos encontram-se estabelecidos do art. 14 ao 16 da CF/88. 
Vejam-se, sobre o tema, as lições de Ferreira (2015, p. 41-42):

É crucial o início do capítulo concernente aos direitos políticos na Constituição afirmar que a soberania popular será exercida pelo sufrágio universal e pelo voto direto e secreto, fortalecendo a concepção e o modo pelo qual esses direitos fundamentais se expressam: pelo domínio do povo cujas marcas históricas são relevantes.

Impende destacar que os direitos políticos não se encerram no direito de votar e ser votado, mas se espraiam para qualquer atividade de participação, pelo povo, da construção de políticas públicas e processos deliberativos de tomada de decisões - tais como referendos e plebiscitos -, bem como na iniciativa popular na criação de leis. Decerto que o voto é a expressão maior desse direito, tendo em vista que é por meio desse instrumento fundamental do cidadão que se escolhem os representantes da nação.

Numa concepção mais alargada desses direitos, que ultrapassa o capítulo IV do Título II (BRASIL, 1988, art. 14-16), as formas de ascensão ao serviço público (BRASIL, 1988, art. 37, I-II) se inserem na concepção mais ampla desses direitos.

A própria Corte Interamericana de Direitos Humanos (Corte $\mathrm{IDH}$ ) reconheceu, no Caso Reverón Trujillo vs. Venezuela, a violação dos direitos políticos de uma juíza exonerada de suas funções, no período de deterioração democrática.

A Convenção Americana de Direitos Humanos (CADH), por exemplo, traz, em seu artigo 23, as hipóteses de restrição dos direitos políticos:

Artigo 23 - Direitos políticos. 1. Todos os cidadãos devem gozar dos seguintes direitos e oportunidades: a) de participar da condução dos assuntos públicos, diretamente ou por meio de representantes livremente eleitos; b) de votar e ser eleito em eleições periódicas, autênticas, realizadas por sufrágio universal e igualitário e por voto secreto, que garantam a livre expressão da vontade dos eleitores; e c) de ter acesso, em condições gerais de igualdade, às funções públicas de seu país. 2. A lei pode regular o exercício dos direitos e das oportunidades, a que se refere o inciso anterior, exclusivamente por motivo de idade, nacionalidade, residência, idioma, instrução, capacidade civil ou mental, ou condenação, por juiz competente, em processo penal. (grifo nosso) 
Ferreira (2015, p. 113) discorre sobre a importância desta norma, porque:

[...] além de assegurar o gozo dos direitos políticos, afirma-se a necessidade de acesso e oportunidade para tanto. A participação nos assuntos públicos e a igualdade na busca pelas funções públicas deve ser vista, também, pela lente do oferecimento de oportunidades para a fruição desses direitos políticos. A "oportunidade" foi definida no Caso Lopez Mendoza vs. Venezuela (\$ 107), como a criação pelo Estado de condições e mecanismos, de "medidas positivas" para a efetividade do direito.

Em face da gravidade dos direitos políticos, a CADH, conforme mencionamos alhures, estabeleceu as únicas hipóteses em que os direitos políticos do cidadão podem ser restringidos, a saber: por motivo de idade, nacionalidade, residência, idioma, instrução, capacidade civil ou mental, ou condenação, por juiz competente, em processo penal. Essa cláusula deve ser lida numerus clausus. O nível da magnitude de tais normas fica ainda mais clarividente quando a $\mathrm{CADH}$, em seu artigo 27 , exclui da possibilidade de suspensão das garantias, em momentos de grave turbação, os direitos políticos, "nem das garantias indispensáveis para a proteção de tais direitos"2.

Os sistemas internacionais de proteção aos direitos humanos não pretendem impor um modelo eleitoral único aplicável a todos os Estados. Ao revés, estabelecem standards mínimos de proteção desses direitos fundamentais, levando em consideração a singularidade de cada país no modo de implementação e organização das eleições. Assim, cada nação tem a competência de escolher, por exemplo, seu modelo de financiamento de campanhas eleitorais e o sistema eleitoral - se proporcional, distrital, majoritário ou misto.

\footnotetext{
${ }^{2}$ Artigo 27 - Suspensão de garantias. 1. Em caso de guerra, de perigo público, ou de outra emergência que ameace a independência ou a segurança do Estado-parte, este poderá adotar as disposições que, na medida e pelo tempo estritamente limitados às exigências da situação, suspendam as obrigações contraídas em virtude desta Convenção, desde que tais disposições não sejam incompatíveis com as demais obrigações que lhe impõe o Direito Internacional e não encerrem discriminação alguma fundada em motivos de raça, cor, sexo, idioma, religião ou origem social. 2. A disposição precedente não autoriza a suspensão dos direitos determinados nos seguintes artigos: 3 (direito ao reconhecimento da personalidade jurídica), 4 (direito à vida), 5 (direito à integridade pessoal), 6 (proibição da escravidão e da servidão), 9 (princípio da legalidade e da retroatividade), 12 (liberdade de consciência e religião), 17 (proteção da família), 18 (direito ao nome), 19 (direitos da criança), 20 (direito à nacionalidade) e 23 (direitos políticos), [...] (grifo nosso).
} 
Com efeito, fica a critério afeito a cada Estado estabelecer o modo e o funcionamento dos direitos políticos fundamentais, cuidando os diplomas internacionais, por seu turno, da proteção desses direitos e do regime democrático.

A disposição do item 2 do artigo 23 da CADH estabelece, taxativamente, as hipóteses em que os direitos políticos podem sofrer restrições. Mais que isso, fundamentos de ordem moral não são capazes de limitar esses direitos. Marcelo Ferreira (2015, p. 115-116), sobre o tema, leciona que:

Ao contrário dos direitos políticos, é de se ressaltar que a liberdade de manifestação e expressão pode, sim, ser mitigada por critérios morais ("moral pública" ou a "proteção moral da infância e da adolescência"), por exemplo, por expressa disposição convencional, de onde se aduz que, quando quis, a Convenção dispôs sobre a matéria. Da mesma maneira, o direito de circulação e de residência que pode ser restrito para a proteção da moral pública (art. 22.3), o direito de reunião (art. 15) e a liberdade de associação (art. 16.2) podem sofrer limitações em nome da moral pública.

Percebe-se, pois, que, quando quis, a CADH estabeleceu como forma de limitação de alguns direitos, fundamentos de ordem moral. Contudo, fê-lo expressamente, não o fazendo em relação aos direitos políticos, cuja cláusula restritiva deve ser lida numerus clausus, taxativamente.

Dissertando sobre os direitos humanos como fundamento dos direitos políticos, José Jairo Gomes (2010, p. 110-113) destaca a positivação desses direitos em diversos diplomas internacionais, concluindo que:

[...] os direitos políticos situam-se entre os direitos humanos e fundamentais, constituindo um subsistema. $\mathrm{O}$ desenvolvimento desse subsistema é sobremodo relevante, pois significa a institucionalização daqueles direitos e dos valores que expressam, e isso é essencial para otimizar a proteção deles.

Ademais, os direitos políticos formam a base do regime democrático (MENDES; BRANCO, 2012, p. 753). No escólio de Sonia Picado (2007, p. 48), os direitos políticos 
[...] são aquele grupo de atributos da pessoa que torna efetiva sua participação como cidadão de um determinado Estado. Em outras palavras, trata-se de faculdades ou, melhor, de titularidades que, juntas, traduzem-se no amplo exercício da participação política. [...] $\mathrm{Na}$ realidade, quando falamos de direitos políticos, fazemos referência às titularidades que desprendem os mecanismos pelos quais a cidadania é exercida ${ }^{3}$. (tradução livre)

Os direitos políticos, tal como hoje os concebemos, encontram sua origem no liberalismo clássico ou dentro dos chamados direitos humanos de primeira geração (ou dimensão), com o fito de limitar as arbitrariedades que a personalização do poder do Estado havia gerado até então.

É, porém, na segunda etapa do constitucionalismo que os direitos políticos adquirem maior "humanidade", através do chamado constitucionalismo pós-guerra ou social, os chamados direitos humanos de segunda geração, uma vez que os direitos políticos se ampliaram para englobar o conceito de democracia. Fato é que, hoje em dia, essa divisão em gerações resta insuficiente para explicar o desenvolvimento dos direitos humanos.

Sobre o enquadramento dos direitos políticos como categoria de direitos humanos, Sonia Picado (2007, p. 49) assevera que:

Tradicionalmente, a questão dos direitos políticos, sua consagração e os meios para a sua tradução em atividades concretas, têm sido objeto do direito constitucional, mas o fato é que, atualmente, os direitos políticos são uma categoria no marco dos direitos humanos e, derivados da dupla faceta que caracteriza os direitos humanos em geral, merecem consideração em dois níveis: constitucional e internacional ${ }^{4}$. (tradução livre)

${ }^{3}[\ldots]$ son aquel grupo de atributos de la persona que hacen efectiva su participación como ciudadano de un determinado Estado. En otras palavras, se trata de faculdades o, mejor, de titularidades que, consideradas en conjunto, se traducen en el ejercicio amplio de la participación política. [...]

En realidad, cuando hablamos de derechos políticos, hacemos referencia a las titularidades de las que se desprenden los mecanismos por medio de los cuales la ciudadania se ejerce.

${ }^{4}$ Tradicionalmente, la cuestión de los derechos políticos, su consagración y los medios para su traducción en actividades concretas, ha sido un tema de derecho constitucional, pero los cierto es que, en la actualidad, los derechos políticos son una categoría en el marco de los derechos humanos y, derivada de la doble faceta que caracteriza a los derechos humanos en general, merecen una consideración en dos planos: constitucional e internacional. 
Nesse cenário, os direitos políticos foram se configurando como categoria de direitos humanos, fato reforçado por sua inclusão em numerosos tratados e convenções que desenvolveram o que hoje conhecemos como direito internacional dos direitos humanos.

Sonia Picado (2007, p. 53) aduz que "os direitos políticos são concebidos dentro do direito internacional dos direitos humanos em virtude de um processo de internacionalização que foi gerado regional e universalmente" . (tradução livre)

No plano internacional, os direitos políticos encontram-se solenemente estabelecidos na Declaração Americana de Direitos e Deveres do Homem (artigo XX), na Declaração Universal dos Direitos do Homem (artigo 21), no Protocolo 1 ao Convênio Europeu para a Proteção dos Direitos Humanos e das Liberdades Fundamentais (artigo 3o), no Pacto Internacional dos Direitos Civis e Políticos (artigo 25), na Convenção Americana de Direitos Humanos (artigo 23), na Carta Democrática Interamericana (artigos $2^{\circ}$ e $3^{\circ}$ ), dentre outras convenções internacionais.

\section{Os direitos políticos das mulheres e os tratados internacionais}

Algumas Constituições trataram da igualdade entre mulheres e homens no que se refere aos direitos políticos de forma expressa, inobstante outras Cartas Políticas positivarem tal igualdade de forma genérica, como é o caso da Constituição do Brasil. A título de exemplo, temos as Constituições da Argentina, de 1994 (art. 37), do Equador, de 1991 (art. 102) ${ }^{6}$, de Nicarágua, de 1987 (art. 48) ${ }^{7}$, e do Paraguai, de 1992 (art. 117) ${ }^{8}$.

\footnotetext{
5 "los derechos políticos se conciben dentro del derecho internacional de derechos humanos en virtud de un proceso de internacionalización que se ha venido generando tanto en lo regional como en lo universal".

${ }^{6} \mathrm{O}$ Estado deve promover e garantir a participação equitativa de mulheres e homens como candidatos nos processos de eleição popular, nas instâncias de direção e decisão na esfera pública, na administração da justiça, em órgãos de controle e nos partidos políticos.

${ }^{7}$ Se estabelece a igualdade incondicional de todos os nicaraguenses no gozo de seus direitos políticos, no exercício desses direitos e no cumprimento de seus deveres e responsabilidades, existe absoluta igualdade entre homens e mulheres. É obrigação do Estado eliminar os obstáculos que efetivamente impedem a igualdade entre os nicaraguenses e sua efetiva participação na vida política, econômica e social do país.

${ }^{8}$ Os cidadãos, sem distinção de sexo, têm o direito de participar dos assuntos públicos, diretamente ou por meio de seus representantes, na forma prevista por esta Constituição e pelas leis. $\mathrm{O}$ acesso das mulheres a funções públicas será promovido.
} 
A partir da internacionalização dos direitos humanos, os direitos políticos das mulheres também foram consagrados em diversos instrumentos internacionais, universais e regionais.

A igualdade de gênero na política foi trazida ao plano internacional pela primeira vez na Convenção sobre os Direitos Políticos da Mulher, de 1953, o qual foi o primeiro instrumento do sistema universal de proteção dos direitos humanos a reconhecer de forma específica e exclusiva o direito à participação política da mulher, cujo preâmbulo indica que o objetivo principal do texto é conceder a homens e mulheres igualdade no gozo e no exercício dos direitos políticos.

A igualdade formal de gênero foi insculpida nos artigos $1^{\circ}, 2^{\circ}$ e $3^{\circ}$ da Convenção, os quais garantem às mulheres, em igualdade de condições com os homens, o direito ao voto em todas as eleições, a elegibilidade para todos os organismos públicos de eleição, bem como de ocupar todos os postos públicos e de exercer todas as funções públicas, tudo sem quaisquer restrições.

Em que pese a Convenção sobre os Direitos Políticos da Mulher reconheça o direito à participação política feminina, carece, entretanto, de estratégias para promoção efetiva dos direitos políticos das mulheres.

Também no plano internacional dos direitos humanos, surge, em 1979, a Convenção das Nações Unidas para a Eliminação de Todas as Formas de Discriminação Contra a Mulher (CEDAW, sua sigla em inglês), ratificada por todos os países da região, que, segundo Line Bareiro (2007, p. 684), é o instrumento internacional de proteção dos direitos humanos mais relevante para remover os obstáculos que impedem a equidade de representação política das mulheres.

$\mathrm{Na}$ esteira de Bareiro, portanto, o instrumento normativo mais importante pela não discriminação contra as mulheres é, indubitavelmente, a CEDAW, a qual, em seu artigo 1ํㅡㄹ estabelece que:

Artigo 1․ Para os fins da presente Convenção, a expressão "discriminação contra a mulher" significará toda distinção, exclusão ou restrição baseada no sexo e que tenha por objeto ou resultado prejudicar ou anular o reconhecimento, gozo ou exercício pela mulher, independentemente de seu estado civil, com base na igualdade do homem e da mulher, dos direitos humanos e liberdades fundamentais nos campos político, econômico, social, cultural e civil, ou em qualquer outro campo. 
A CEDAW insculpiu a igualdade política entre homens e mulheres no artigo 7º, impondo aos Estados-partes a adoção de medidas apropriadas para eliminar a discriminação contra a mulher na vida política e pública do país, garantindo igualdade de condições com os homens, o direito a: votar em todas as eleições e referendos públicos e ser elegível para todos os órgãos cujos membros sejam objeto de eleições públicas; participar na formulação de políticas governamentais e na execução destas, e ocupar cargos públicos e exercer todas as funções públicas em todos os planos governamentais; e, por último, participar em organizações e associações não governamentais que se ocupem da vida pública e política do país.

Há que se fazer referência também a outro dispositivo que explicita as medidas de caráter transitório para efetivar a igualdade substantiva entre homem e mulher, as quais não serão consideradas como discriminatórias:

Artigo 4 - 1. A adoção pelos Estados-partes de medidas especiais de caráter temporário destinadas a acelerar a igualdade de fato entre o homem e a mulher não se considerará discriminação na forma definida nesta Convenção, mas de nenhuma maneira implicará, como consequência, a manutenção de normas desiguais ou separadas; essas medidas cessarão quando os objetivos de igualdade de oportunidade e tratamento houverem sido alcançados.

O dispositivo supra está em consonância com aquilo que a doutrina ao norte citada explicita: há a necessidade de adoção de medidas de discriminação inversa/positiva que reduzam, da forma mais rápida possível, a abissal desigualdade entre os gêneros. Atingida a plena igualdade, cessará a necessidade de sua utilização.

$\mathrm{O}$ artigo $8^{\circ}$ da CEDAW positiva as medidas para garantir, em igualdade de condições com o homem e sem discriminações, a representação governamental das mulheres no plano internacional e nos trabalhos das organizações internacionais.

Em seu artigo 17, estabelece a conformação e o funcionamento do Comitê sobre a Eliminação da Discriminação contra a Mulher, cuja atribuição consiste em examinar os progressos na aplicação da CEDAW pelos Estados-partes, que compreende quatro principais funções:

[...] diálogo construtivo com os Estados-partes, por meio de recomendações e observações; pedidos de medidas provisórias (artigo 5o, Protocolo Facultativo à Convenção sobre a Eliminação de Todas 
as Formas de Discriminação contra a Mulher) e recomendações em casos individuais (artigo 7º Protocolo), preparação de relatórios de investigação (artigo 8o, Protocolo) e recomendações gerais (artigo $21, \mathrm{CEDAW})^{9}$. (tradução livre)

Nessa senda, os Estados-partes devem remeter, periodicamente, ao Secretário-Geral das Nações Unidas, para análise do Comitê, relatórios sobre as medidas legislativas, judiciárias, administrativas ou outras que adotarem para tornarem efetivas as disposições da CEDAW, de modo a possibilitar uma avaliação acerca de sua aplicação no plano nacional.

O Comitê, que se reúne pelo menos uma vez por ano por um período não superior a duas semanas, se encarrega de examinar os Relatórios (artigo 20). Os países, além de informar sobre as medidas aplicadas e os avanços, também apontam fatores e dificuldades que afetam o grau de cumprimento da Convenção. O Comitê faz sugestões e recomendações, com base no exame dos Relatórios e nos dados fornecidos pelos países ${ }^{10}$. (tradução livre)

Ademais, a observância da CEDAW é vinculante para todos os poderes do Estado (Executivo, Legislativo e Judiciário), de modo que devem, conjuntamente, envidar esforços para garantir seu cumprimento, vez que são os governos os responsáveis por cumprir as obrigações contidas no referido instrumento e, mais do que isso, prestar contas.

Nesse contexto, o Comitê da CEDAW insiste no estabelecimento de mecanismos efetivos de prestação de contas e na implementação transparente, coerente e sistemática da Convenção em todo o território (nacional, regional e local) (FLORES SALAZAR, 2016, p. 58).

\footnotetext{
${ }^{9}$ Diálogo constructivo con los Estados partes, mediante recomendaciones y observaciones; solicitudes de medidas previsionales (artículo 5, Protocolo Facultativo de la Convención sobre la Eliminación de todas las formas de Discriminación contra la Mujer) y recomendaciones en casos individuales (artículo 7, Protocolo), confección de informes de investigación (artículo 8, Protocolo) y recomendaciones generales (artículo 21, CEDAW) (FLORES SALAZAR, 2016, p. 57).

${ }^{10}$ El Comité, que se reúne una vez al año mínimamente, por un periodo no superior a las dos semanas, se encarga de examinar los Informes (artículo 20). Los países, además de informar acerca de las medidas aplicadas y los progresos, también puntualizan en factores y dificultades que afectan el grado de cumplimiento de la Convención. El Comité hace sugerencias y recomendaciones, con base en el examen de los Informes y los datos que proporcionan los países (FLORES SALAZAR, 2016, p. 57-58).
} 
O Comitê CEDAW emite recomendações de caráter geral com o objetivo de esclarecer, ampliar e complementar artigos que guardam relação com a não discriminação. No que se refere à participação política das mulheres, o Comitê emitiu as Recomendações Gerais nos 23, 25 e 28, as quais trouxeram importantes contribuições no tocante à participação política das mulheres.

À guisa de exemplo, no parágrafo 22 da $R G n^{\circ} 25$, o Comitê esclarece confusão conceitual gerada pelo emprego equivocado das expressões "equidade" e "igualdade" como sinônimos. Tanto o alcance quanto a natureza das expressões são distintos, uma vez que a primeira se refere à tratamento justo, enquanto que os objetivos da CEDAW são a não discriminação e a igualdade de fato e de direito entre homens e mulheres, devendo os Estados utilizarem a expressão "igualdade":

Os Estados-partes são instados a utilizar exclusivamente os conceitos de igualdade entre a mulher e o homem ou a igualdade de gênero e não o conceito de equidade de gênero no cumprimento de suas obrigações em virtude da Convenção. Em algumas jurisdições, o último conceito é usado para se referir ao tratamento justo da mulher e do homem, de acordo com suas respectivas necessidades. Isso pode incluir tratamento igual ou tratamento diferente, mas considerado equivalente em termos de direitos, benefícios, obrigações e oportunidades ${ }^{11}$. (tradução livre)

Em relação ao Brasil, o Comitê (2003) manifestou preocupação porque o processo de aplicação da cota eleitoral de gênero - que será objeto de estudo no próximo capítulo - é controvertido e carece de eficácia, propondo sanções para o descumprimento. Passados alguns anos (2007), continuou apontando deficiências na aplicação dessas medidas especiais, catalogando a Lei n⿳o 9.504/1997 (Lei das Eleições) como instrumento de resultado ineficaz e de pouco efeito.

${ }^{11}$ Se exhorta a los Estados partes a utilizar exclusivamente los conceptos de igualdad entre la mujer y el hombre o la igualdad entre los géneros y no el concepto de equidad entre los géneros al cumplir con sus obligaciones en virtud de la Convención. En algunas jurisdicciones este último concepto se utiliza para referirse al trato justo de la mujer y el hombre en función de sus necesidades respectivas. Esto puede incluir un trato igual, o un trato diferente pero considerado equivalente en cuanto a los derechos, los beneficios, las obligaciones y las oportunidades. 
Essa ineficácia para colocar em prática o mecanismo de cota de participação política se configura como eixo central das observações do Comitê CEDAW (2012), que se preocupa com questões mais pontuais como difundir informação sobre sua aplicação e avaliar suas repercussões e impactos.

Relaciona a ineficiência no uso das medidas com atitudes patriarcais, estereótipos e fragilidades nos mecanismos que garantem sua aplicação (Brasil 2012); aduz falta de conscientização e interesse dos partidos políticos (Panamá 2010). Argumenta que a falta de medidas especiais e a persistência de estereótipos e atitudes patriarcais no Chile (2012) são fatores que dificultam a participação das mulheres, assim como o machismo, a falta de recursos, a assistência técnica e os conhecimentos das mulheres para apresentar suas candidaturas na República Dominicana (2013). No caso da Colômbia (2013), apresenta mecanismos que asseguram a cota de $30 \%$ de mulheres nas listas eleitorais, em posições com possibilidades de vencer; que os partidos políticos alocam o orçamento para campanhas de mulheres e estabeleçam sanções, indicadores e cronogramas de cumprimento (Colômbia, 2013). Manifesta a sua preocupação sobre a não aplicação de medidas especiais em Cuba (2013), Chile (2012) e Venezuela (2014) e recomenda a sua adopção, especialmente para grupos de mulheres insuficientemente representadas, como as de ascendência africana, as idosas, indígenas, deficientes e rurais, e em nível local ${ }^{12}$.(tradução livre)

${ }^{12}$ Relaciona la ineficacia en el uso de las medidas con actitudes patriarcales, estereotipos y debilidad en los mecanismos que velan por que se aplique (Brasil 2012); aduce falta de conciencia e interés de los partidos políticos (Panamá 2010). Argumenta que la falta de medidas especiales y la persistencia de estereotipos y actitudes patriarcales en Chile (2012) son factores que obstaculizan la participación de las mujeres, como también lo son el machismo y la falta de recursos, la asistencia técnica y los conocimientos de las mujeres para presentar sus candidaturas en República Dominicana (2013). En el caso de Colombia (2013), presenta mecanismos que aseguren la cuota de 30\% de mujeres en las listas electorales, en puestos con posibilidades de ganar; que los partidos políticos asignen presupuesto a las campañas de las mujeres y se establezcan sanciones, indicadores y calendarios de cumplimiento (Colombia 2013). Manifiesta preocupación por la no aplicación de medidas especiales en Cuba (2013), Chile (2012) y Venezuela (2014) y recomienda su adopción, especialmente para grupos de mujeres insuficientemente representados, como mujeres de ascendencia africana, adultas mayores, indígenas, mujeres con discapacidad y mujeres rurales y en el ámbito local (FLORES SALAZAR, 2016, p. 70-71). 
Outro importante diploma internacional a estabelecer a igualdade quanto aos direitos políticos entre homens e mulheres é o Pacto Internacional dos Direitos Civis e Políticos (PIDCP), o qual preconiza, em seu artigo 3o, que os Estados-partes comprometem-se a assegurar a homens e a mulheres igualdade no gozo de todos os direitos civis e políticos enunciados no Pacto. $\mathrm{O}$ artigo $2^{\circ}$ dispõe sobre a necessidade de os Estados implementarem medidas legislativas destinadas a promover o respeito a tais direitos, sem qualquer forma de discriminação, inclusive em razão do sexo.

Por seu turno, o artigo 25 assenta que todo cidadão terá o direito e a possibilidade de participar da condução dos assuntos públicos, diretamente ou por meio de representantes livremente escolhidos; de votar e de ser eleito em eleições periódicas, autênticas, realizadas por sufrágio universal e igualitário e por voto secreto, que garantam a manifestação da vontade dos eleitores; e de ter acesso, em condições gerais de igualdade, às funções públicas de seu país.

O Comitê de Direitos Humanos das Nações Unidas, que monitora o cumprimento do PIDCP, formulou a Observação Geral n 28 para melhor compreensão do alcance do artigo 3º, o qual trata da igualdade de direitos entre homens e mulheres. No parágrafo 29, consignou:

O direito de participar da vida pública não se materializa plenamente e em condições de igualdade em todos os lugares. Os Estados-partes devem assegurar que a lei garanta à mulher os direitos contidos no artigo $25 \mathrm{em}$ pé de igualdade com o homem e adote medidas efetivas e positivas, incluindo as medidas necessárias de discriminação inversa, para promover e assegurar a participação da mulher nos assuntos públicos e no exercício de cargos públicos. As medidas efetivas adotadas pelos Estados-partes para assegurar que todas as pessoas com direito ao voto possam exercê-lo não devem discriminar ninguém em razão do sexo. O Comitê solicita aos Estados-partes que apresentem informações estatísticas sobre a porcentagem de mulheres que ocupam cargos eletivos, incluindo o Poder Legislativo e altos cargos da administração pública e do Poder Judiciário ${ }^{13}$. (tradução livre)

\footnotetext{
${ }^{13} \mathrm{El}$ derecho a participar en la vida pública no se materializa plenamente y en condiciones de igualdad en todas partes. Los Estados Parte deberán cerciorarse de que la ley garantice a la mujer los derechos contenidos en el artículo 25 en pie de igualdad con el hombre y adoptar medidas eficaces y positivas, incluidas las medidas necesarias de discriminación inversa, para promover y asegurar la participación de la mujer en los asuntos públicos y en el ejercicio de cargos públicos. Las medidas efectivas que adopten los Estados Parte para
} 
Os instrumentos internacionais que preveem a igualdade de gênero na esfera política não se encerram nesses que foram citados. Existem outros diplomas que também tratam da questão da igualdade na representação política entre homens e mulheres, a exemplo da Convenção Americana de Direitos Humanos (Pacto de São José da Costa Rica) ${ }^{14}$, da Declaração Universal dos Direitos Humanos ${ }^{15}$, da Declaração Americana dos Direitos e Deveres do Homem ${ }^{16}$, do Estatuto de Roma ${ }^{17}$, a Convenção Interamericana para Prevenir, Punir e Erradicar a Violência contra a Mulher (Convenção

velar por que todas las personas con derecho a voto puedan ejercerlo no deben discriminar por razón de sexo. El Comité pide a los Estados Parte que presenten información estadística acerca del porcentaje de mujeres que desempeñan cargos de elección pública, con inclusión del Poder Legislativo y de altos cargos de la administración pública y el Poder Judicial (BAREIRO, 2007, p. 685).

${ }_{14}$ Artigo 23, I. Todos os cidadãos devem gozar dos seguintes direitos e oportunidades: a) de participar na direção dos assuntos públicos, diretamente ou por meio de representantes livremente eleitos; b) de votar e ser eleitos em eleições periódicas autênticas, realizadas por sufrágio universal e igual, e por voto secreto que garanta a livre expressão da vontade dos eleitores; e c) de ter acesso, em condições gerais de igualdade, às funções públicas de seu país.

${ }^{15}$ Artigo 21. 1. Toda pessoa tem o direito de tomar parte na direção dos negócios públicos do seu país, quer diretamente, quer por intermédio de representantes livremente escolhidos. 2. Toda a pessoa tem direito de acesso, em condições de igualdade, às funções públicas do seu país. 3. A vontade do povo é o fundamento da autoridade dos poderes públicos e deve exprimir-se através de eleições honestas a realizar periodicamente por sufrágio universal e igual, com voto secreto ou segundo processo equivalente que salvaguarde a liberdade de voto.

${ }^{16}$ Artigo XX. Toda pessoa, legalmente capacitada, tem o direito de tomar parte no governo do seu país, quer diretamente, quer através de seus representantes, e de participar das eleições, que se processarão por voto secreto, de uma maneira genuína, periódica e livre.

${ }^{17}$ Artigo 36, 8, a, III. Na seleção dos juízes, os Estados Partes ponderarão sobre a necessidade de assegurar que a composição do Tribunal inclua uma representação justa de juízes do sexo feminino e do sexo masculino. 
de Belém do Pará) ${ }^{18}$, a Convenção Interamericana Sobre a Concessão dos Direitos Políticos da Mulher ${ }^{19}$, a Carta Democrática Interamericana ${ }^{20}$, etc.

Destarte, com relação ao direito à participação política, tanto o sistema universal quanto o sistema interamericano de proteção dos direitos humanos preveem instrumentos gerais ou específicos que promovem o direito das mulheres de participar nas decisões políticas de seu país, bem como ocupar cargos públicos e que reconhecem a importância e a necessidade de que os Estados-partes adotem medidas afirmativas que permitam a efetiva incorporação de mulheres na arena política.

Sonia Picado (2007, p. 58) assevera, no entanto, que as democracias representativas na América Latina são associadas aos homens:

A atividade política na América Latina centrou-se no modelo das democracias representativas, no qual a política esteve diretamente relacionada à esfera pública e, dentro dela, inferiu-se que a atividade democrática é uma extensão das atividades de ampla visibilidade social que, em geral, têm sido historicamente associadas aos homens ${ }^{21}$.(tradução livre)

Daí a importância de se pôr em prática mecanismos que reconheçam as desigualdades de gênero, de maneira a garantir um acesso efetivo e igualitário das mulheres nas esferas onde são tomadas as decisões políticas.

Em virtude da incorporação dos principais tratados internacionais de proteção dos direitos humanos (políticos das mulheres) no ordenamen-

${ }^{18}$ Artigo 4․ Toda mulher tem direito ao reconhecimento, desfrute, exercício e proteção de todos os direitos humanos e liberdades consagrados em todos os instrumentos regionais e internacionais relativos aos direitos humanos. Estes direitos abrangem, entre outros: [...] j) direito a ter igualdade de acesso às funções públicas de seu país e a participar nos assuntos públicos, inclusive na tomada de decisões.

19 Artigo 1‥ As Altas Partes Contratantes convêm em que o direito ao voto e à eleição para um cargo nacional não deverá negar-se ou restringir-se por motivo de sexo.

${ }^{20}$ Artigo 28. Os Estados promoverão a participação plena e igualitária da mulher nas estruturas políticas de seus respectivos países, como elemento fundamental para a promoção e o exercício da cultura democrática.

${ }^{21}$ La actividad política en América Latina se ha centrado en el modelo de las democracias representativas, en el que la política se ha relacionado en forma directa con la esfera pública y, dentro de ella, se ha inferido que la actividad democratica es una prolongación de las actividades de amplia visibilidad social que, por lo general, han estado históricamente asociadas a los varones. 
to jurídico pátrio por força do art. 5ำ $\int 2^{\circ}$, da CF, os juízes nacionais estão obrigados a aplicá-los no exercício da jurisdição, procedendo, caso necessário ao controle difuso de convencionalidade, caso alguma lei doméstica esteja em desacordo com a proteção dos direitos políticos das mulheres estabelecidos nos diplomas internacionais. Soma-se a isso o fato de que o descumprimento ou violação aos direitos políticos humanos das mulheres consignados nos tratados poderá acarretar aos Estados-partes sanções aplicadas pelos organismos internacionais.

\subsection{Casos de violação aos direitos políticos das mulheres apre- sentados à Comissão Interamericana de Direitos Humanos}

Vários países do mundo, inclusive na América Latina, introduziram em seus ordenamentos medidas especiais de promoção à participação da mulher na política, a chamada "cota de gênero". Assim, Argentina (1991), México (1996), Paraguai (1996), Costa Rica (1996), Brasil (1997), Peru (1997), Bolívia (1997), Equador (1997) e República Dominicana (1997) possuem leis eleitorais que asseguram percentual mínimo de mulheres nas listas de candidatos ao Poder Legislativo.

Ainda que algumas legislações se refiram à cota como sendo "de gênero", isto é, de mulher ou de homem, decerto que sua finalidade precípua é, justamente, promover o incremento da participação feminina na política, tendo em vista que as mulheres são historicamente excluídas da vida pública.

A jurisprudência latino-americana - inclusive a brasileira - revela que são os próprios partidos políticos e os órgãos eleitorais que promovem o descumprimento da legislação de cotas. Dois casos chegaram ao conhecimento da $\mathrm{CIDH}$ e foram admitidos, os quais serão objetos de análise a seguir.

\subsubsection{María Merciadri de Moroni vs. Argentina}

Impende, precipuamente, consignar que este caso, apresentado perante a CIDH em 2001, foi determinante para que a Argentina se tornasse modelo mundial no tocante à ampla participação feminina na política, contando, atualmente, com 38,9\% de representação na Câmara dos Deputados e $41,7 \%$ no Senado.

Em 15 de junho de 1994, María Merciadri de Moroni, filiada ao partido Unión Cívica Radical, após esgotar os recursos internos, apresentou Resenha Eleitoral (Florianópolis), v. 23, n. 1, p. 109-138, 2019 
petição perante a CIDH, na qual alegou que o Estado argentino violou seu direito ao devido processo (artigo $8^{\circ}$ ), seus direitos políticos (artigo 23), direito à igual proteção perante a lei (artigo 24), bem como direito à proteção judicial (artigo 25), todos previstos na CADH.

María Merciadri argumentou que o referido partido político apresentou lista com seis candidatos a deputados nacionais, para as eleições de 03.10.1993, pela Província de Córdoba, alocando duas mulheres, respectivamente, na quarta e na sexta posição da lista de candidatos. Aduziu que tal conformação, realizada de comum acordo entre os dirigentes partidários, violava a Lei $\mathrm{n}^{\mathrm{O}}$ 24.012/1991 (Lei de Cotas), bem como o Decreto governamental no 379/93 - que regulamentou a Lei de Cotas argentina -, a qual exigia que pelo menos duas mulheres figurassem entre os cinco primeiros candidatos da lista, bem como estabelecia um percentual mínimo de 30\% de candidatas aos cargos de eleição em condições proporcionais às chances de serem eleitas.

A lei também estabelece o direito dos cidadãos votantes sob o direito constitucional do sufrágio, para poderem votar listas de candidatos em que as mulheres são representadas de acordo com a fórmula que a lei estipula. O próprio decreto regulamentador preconizava que, quando houvesse cinco lugares a serem preenchidos, dois deveriam ser reservados às mulheres. Essa disposição é de observância obrigatória para os partidos políticos quando montam suas listas de candidatos, e a consequências pelo descumprimento é a negação da certificação.

María alegou que, na condição de cidadã filiada àquela agremiação política, impugnou a lista perante a Junta Eleitoral, que foi rejeitada por considerar "que a lista de candidatos emergiu do consenso de todos os núcleos do partido, que concordaram em uma única lista". Depois de apelar dessa decisão, o tribunal federal rejeitou sua solicitação e declarou que não tinha legitimidade para agir. A peticionária recorreu e a Câmara Federal Eleitoral também rejeitou sua legitimidade para agir, exigindo-lhe interesse próprio. Merciadri considera que a lista do partido Unión Cívica Radical vulnera o direito do eleitor de que haja real igualdade de oportunidades entre homens e mulheres para o acesso a cargos eletivos e qualquer cidadão-eleitor tem o direito de impugnar sem que seja necessário que se trata de pessoa prejudicada pelo lugar que ocupa na lista eleitoral. Cita também o artigo 57 da Lei Orgânica de Partidos Políticos no 23.298, que reconhece a personalidade de filiados aos partidos políticos "quando forem negados direitos concedidos 
pela Carta Orgânica e se encontrarem esgotadas as instâncias partidárias” (CIDH, 2001, online).

Noutras palavras, a peticionária manejou os recursos internos disponíveis perante os tribunais domésticos. Entretanto, não apenas rejeitaram sua queixa, mas também negaram sua legitimidade processual para ação, uma vez que sua demanda carecia de interesse próprio, pois sequer havia sido candidata.

Em 18 de outubro de 1993, María interpôs recurso perante a Suprema Corte argentina, o qual foi indeferido em 2 de dezembro de 1993, alegando-se que:

[...] a petição da recorrente é abstrata, uma vez que as eleições de 3 de outubro de 1993, a Unión Cívica Radical obteve, no distrito em questão, um fluxo de votos que produziu a consagração de quatro deputados nacionais e a discussão dos autos seria sobre quem deveria ter ocupado a quinta posição (VILLANUEVA FLORES, 2009, p. $294)^{22}$. (tradução livre)

María Merciadri considerou que a questão "não foi abstrata” porque se deve reconhecer "direito em expectativa”, uma vez que havia possibilidade in concreto de haver, eventualmente, vacância de uma vaga entre os eleitos. Se a vacância ocorresse, naquelas condições, ascenderia um homem - o quinto colocado - e não uma mulher. Portanto, uma mulher deveria ter sido colocada na quinta posição e um homem na sexta posição e que, mesmo no caso de quatro posições para preencher, duas mulheres deveriam ser escolhidas, porque uma mulher apenas representaria $25 \%$, percentual menor que o exigido pela Lei de Cotas argentina.

Destarte, a peticionária alegou que o Estado argentino violou os artigos 8 e 25 da Convenção Americana de Direitos Humanos porque o tribunal de primeira instância havia considerado que não tinha legitimidade para agir. Da mesma forma, considerou que, ao rejeitar sua demanda, a Corte Suprema de Justiça da Nação violou o princípio de igualdade insculpido no artigo 24, o que implica, por sua vez, um cerceamento dos direitos políticos previstos no artigo 23 da Convenção Americana.

22 [...] la petición de la recurrente resulta abstracta desde que - celebradas las elecciones el 3 de octubre de 1993, la Unión Cívica Radical obtuvo en el distrito en cuestión, un caudal de votos que le produjo la consagración de cuatro diputados nacionales y en autos se debate quién debería haber ocupado la quinta candidatura (VILLANUEVA FLORES, 2009, p. 294). 
Villanueva Flores (2009, p. 294) resume os argumentos levantados pelo Estado argentino em contraponto às alegações formuladas por María Merciadri de Moroni:

Entre outros argumentos, [...] alegou que não cabia à CIDH examinar a integração das listas de candidatos. Da mesma forma, indicou que tal integração não poderia ser entendida como uma violação de qualquer dos direitos estabelecidos na Convenção Americana. O Estado também alegou a doutrina da quarta instância, mediante a qual a CIDH não pode atuar como tribunal de apelação para examinar os supostos erros de fato ou de direito que possam ter sido cometidos pelos tribunais nacionais ${ }^{23}$. (tradução livre)

Em 21 de setembro de 1999, por meio do Relatório no 102/99, a CIDH admitiu o caso. Em 8 de março de 2001, as partes - Ministro das Relações Exteriores Adalberto Rodríguez Giavarini, representando a Argentina, e María Teresa Merciadri de Moroni - subscreveram um acordo de solução amistosa. Segundo consta do supracitado Relatório, o então Presidente da Argentina, Fernando de la Rúa, com a finalidade de chegar a um acordo, expediu, em 28 de dezembro de 2000, o Decreto no 1246, cuja finalidade era regulamentar a Lei de Cotas, derrogando o Decreto Regulamentar $n^{\circ} 379 / 93$.

Para se compreender o impacto da representação formulada por María Merciadri perante a CIDH, impende colacionar excertos da parte de "considerandos" do Decreto no $1246 / 2000$, in verbis:

Que, ao se expedir o Decreto 379/93, levou-se em conta a necessidade de unificar pela via da regulamentação, os critérios gerais para a aplicação da referida norma, para que todos os partidos políticos e coligações dessem um tratamento homogêneo ao tema, tentando evitar posteriores impugnações partidárias ou judiciais.

Que, apesar desta intenção, os diferentes critérios aplicados pelos vários partidos políticos e também julgamentos dissonantes dos res-

\footnotetext{
${ }^{23}$ Entre otros argumentos, [...] alegó que no correspondía a la CIDH examinar la integración de las listas de candidatos electorales. Igualmente, señaló que dicha integración no podía entenderse como violación de alguno de los derechos establecidos en la Convención Americana. El Estado también alegó la doctrina de la cuarta instancia, por la cual la CIDH no puede hacer las veces de un tribunal de alzada para examinar los supuestos errores de hecho o de derecho que puedan haber cometido los tribunales nacionales.
} 
pectivos tribunais, tornam necessário emitir uma regra que leve em conta as mais claras e garantidoras interpretações judiciais.

Que significativos os casos que não foram capazes de chegar ao mais alto tribunal da nação, dado o curto espaço de tempo entre a impugnação da lista e o dia da eleição.

Que esta situação não mudou, a despeito da clara disposição do artigo 37 da Constituição Nacional, em vigor desde 1994, nem das disposições do artigo 4.1 da Convenção sobre a Eliminação de Todas as Formas de Discriminação contra a Mulher - que possui hierarquia constitucional de acordo com o artigo 75, inciso 22, da Constituição Nacional reformada em 1994.

Que se deve ter em conta que um dos critérios mais divergentes corresponde à posição de mulheres candidatas nas listas, o que levou, em muitos casos, que estas estivessem conformadas por homens nos lugares esperados, contrariando as disposições da referida Lei $\mathrm{n}^{\mathrm{o}}$ 24.012, que indica claramente que as mulheres devem ocupar pelo menos trinta por cento $(30 \%)$ da lista em posições com possibilidade de serem eleitas.

Que por todo o exposto e tendo em conta as disposições da Constituição Nacional e a Comissão Interamericana de Direitos Humanos declarou admissível o Caso no 11.307 - María Merciadri Morini - Argentina e foi colocado à disposição das partes com a finalidade de alcançar uma solução amistosa baseada no respeito pelos direitos consagrados na Convenção Americana de Direitos Humanos, torna-se indispensável a revogação do Decreto n 379/93 e expedição de uma norma que efetivamente garanta o cumprimento das disposições da Lei no 24.012, da Constituição Nacional e dos tratados internacionais de direitos humanos, que têm uma hierarquia constitucional (CIDH, 2001, online) (tradução livre) ${ }^{24}$.

${ }^{24}$ Que, al dictarse el Decreto $\mathrm{n}^{\circ} 379 / 93$, se tuvo en cuenta la necesidad de unificar por la vía de la reglamentación, los criterios generales en la aplicación de la norma citada, a fin de que en todos los Partidos Políticos y Alianzas se dé un tratamiento homogéneo al tema tratando de evitar posteriores impugnaciones partidarias o judiciales.

Que, a pesar de esta intención, el diferente criterio aplicado por los distintos partidos políticos y los fallos también discordantes de los respectivos tribunales, hacen indispensable dictar una norma que tenga en cuenta las más claras y garantizadoras interpretaciones judiciales.

Que son significativos los casos que no han podido llegar al más alto Tribunal de la Nación dado el escaso tiempo que corre desde la impugnación de la lista y el día de la elección.

Que esta situación no se ha modificado a pesar de la clara disposición del artículo 37 de la Constitución Nacional, en vigencia desde 1994, ni de lo dispuesto por el artículo 4.1 de la 
Nessa senda, faz-se mister trazer a lume o disposto nos artigos $3^{\text {o }}$ e 11 do referido decreto:

Artigo 3ำ - A percentagem mínima exigida pelo artigo 60 do Código Eleitoral Nacional substituído pela Lei no 24.012 será aplicada a todos os candidatos da respectiva lista que cada Partido Político, Confederação ou Coligação indicar, mas só será considerada cumprida quando também for aplicada ao número de cargos que o Partido Político, a Confederação ou a Coligação renovarem na referida eleição.

Artigo 11 - Todas as pessoas inscritas no Registro Eleitoral de um Distrito têm o direito de impugnar perante a Justiça Eleitoral qualquer lista de candidatos, quando considerarem que fora conformada em violação à Lei nº 24.012 (CIDH, 2001, online) (tradução livre) ${ }^{25}$.

A Argentina foi o primeiro país da América Latina a estabelecer uma política de cota feminina nas listas de candidatos aos cargos eletivos

Convención sobre la Eliminación de todas las Formas de Discriminación contra la Mujer - que posee jerarquía constitucional conforme al artículo 75, inciso 22, de la Constitución Nacional reformada en 1994.

Que debe tenerse en cuenta que uno de los criterios más divergentes corresponde a la ubicación de las candidatas mujeres en las listas, lo que ha motivado en muchos casos que estas estén conformadas por varones en los lugares expectables, contrariando lo dispuesto por la referida Ley $\mathrm{n}^{\mathrm{0}}$ 24.012, que claramente indica que las mujeres deben ocupar como mínimo el treinta por ciento $(30 \%)$ de la lista en lugares con posibilidad de resultar electas. Que por todo lo expuesto y teniendo en cuenta las disposiciones de la Constitución $\mathrm{Na}$ cional, así como que la Comisión Interamericana de Derechos Humanos ha declarado admisible el Caso no 11.307 - María Merciadri de Morini - Argentina y se ha puesto a disposición de las partes con el fin de alcanzar una solución amistosa fundada en el respeto de los derechos consagrados en la Convención Americana sobre Derechos Humanos, se torna indispensable la derogación del Decreto Reglamentario no $379 / 93$ y el dictado de una norma que garantice efectivamente el cumplimiento de las disposiciones de la Ley $\mathrm{n}^{\circ}$ 24.012, la Constitución Nacional y los tratados internacionales de derechos humanos, que poseen jerarquía constitucional (CIDH, 2001, online).

${ }^{25}$ Artículo $3^{\text {o }}$ - El porcentaje mínimo requerido por el artículo 60 del Código Electoral Nacional sustituido por la Ley no 24.012. se aplicará a la totalidad de los candidatos de la lista respectiva que cada Partido Político, Confederación o Alianza Transitoria nomine, pero sólo se considerará cumplido cuando se aplique también al número de cargos que el Partido Político, Confederación o Alianza Transitoria renueve en dicha elección.

Artículo $11^{\circ}$ - Todas las personas inscriptas en el Padrón Electoral de un Distrito tienen derecho a impugnar ante la Justicia Electoral cualquier lista de candidatos cuando consideren que ésta se ha conformado violando la Ley no 24.012 (CIDH, 2001, online). 
como condição de sua oficialização, em porcentagem não menor do que $30 \%$, por meio da Lei nํㅡ 24.012 de 1991, que modificou o Código Eleitoral argentino, introduzindo no ordenamento jurídico daquele país ação positiva/afirmativa de acesso aos mandatos populares (AMAYA, 2016, p. 92-93).

Essa disposição legislativa foi fortalecida a partir da reforma constitucional de 1994, a qual incorporou o princípio da igualdade real de oportunidades entre homens e mulheres, atribuindo ao Congresso argentino a tarefa de legislar e promover medidas de ação positiva que garantam tal igualdade.

A Argentina - que optou pelo sistema proporcional de lista fechada-, atualmente, serve como modelo de participação da mulher na política, contando, atualmente, com 38\% de representação feminina na Câmara dos Deputados e 41\% no Senado, ocupando a 18 posição no ranking mundial (IPU, 2019).

\subsubsection{Janet Espinoza Feria e outras vs. Peru}

Em 2 de agosto de 2001, Walter Albán Peralta, na qualidade de Defensor del Pueblo en funciones, e Victoria Villanueva Chávez, na condição de coordenadora geral do Movimento Manuela Ramos, apresentaram uma petição perante à $\mathrm{CIDH}$, na qual alegam violação aos direitos políticos (artigo 23), a igualdade perante a lei (artigo 24) e o direito à não discriminação (artigo 1.1), preconizados na CADH, por parte da República do Peru, em prejuízo às candidatas aos Congresso da República dos distritos eleitorais de Callao, Ica e La Libertad e os eleitores Janet Espinoza Feria, Katia Iliana Chumo García e outros.

$\mathrm{O}$ art. 116 da Lei Orgânica de Eleições peruana (Lei $\mathrm{n}^{\circ}$ 26.859/1997), modificada pela Lei $n^{\circ}$ 27.387, estabelece que as listas de candidatos para o Congresso devem incluir um número não inferior a $30 \%$ de mulheres ou de homens.

Alegam os peticionários que as autoridades eleitorais do Peru, em uma interpretação restritiva da Lei Eleitoral 26.859 que estabelece, entre outras disposições, as cotas eleitorais como ação afirmativa para promover a participação e o acesso das mulheres nos processos eleitorais em no mínimo $30 \%$, favoreceram a discriminação de gênero por meio da edição da Resolução n. ${ }^{\circ}$ 068-2001, de 22 de janeiro de 2001, a qual fixou em três dos vinte e cinco distritos eleitorais do país - quais sejam, Callao, Ica e La Libertad -, cotas eleitorais inferiores ao mínimo legal de 30\% para as eleições do Congresso realizadas em abril de 2001. 
Indicam que, efetivamente, para o Distrito de Ica, com direito a eleger quatro congressistas, o mínimo de um candidato masculino ou feminino para cada lista foi regulamentado. Já no Distrito de La Libertad, com direito a eleger sete congressistas, o mínimo de dois candidatos do sexo masculino ou feminino foi regulado para cada lista. No Distrito de Callao, por sua vez, com o direito de eleger quatro congressistas, o mínimo de um candidato masculino ou feminino para cada lista foi regulamentado.

Com efeito, nos distritos eleitorais de Ica e Callao, a cota de mulheres foi reduzida para $25 \%$ do total de candidatos de cada lista, e no distrito de La Libertad, a cota de mulheres foi reduzida para 28,5\%.

Consectariamente, com a fixação, por intermédio da resolução supramencionada, de percentuais mínimos abaixo do previsto na Lei Orgânica de Eleições, não se conseguiu eleger um número maior de mulheres nas eleições de 8 de abril de 2001.

O Defensor do Povo provocou, em 31 de janeiro de 2001, o Jurado Nacional de Elecciones, órgão competente para assegurar o cumprimento das regras eleitorais, a fim de alterar a Resolução n. ${ }^{\circ}$ 068-2001-JNE, com o fito de dar cumprimento à Lei Eleitoral, no sentido de fixar em dois o número mínimo de candidatas para os distritos eleitorais de Ica e Callao, e em três para o distrito eleitoral de La Libertad, levando em conta as disposições do artigo 116 da Lei Orgânica de Eleições, quando preconiza que "as listas de candidatos para o Congresso em cada distrito eleitoral devem incluir um número não inferior a 30\% de mulheres ou homens".

Um pedido semelhante formulado ao mesmo órgão foi realizado pela Presidente da Comissão da Mulher e Desenvolvimento Humano do Congresso da República, bem como pelo Movimento Manuela Ramos (VILLANUEVA FLORES, 2009, p. 297).

O Jurado Nacional de Elecciones, ignorando a natureza das ações afirmativas, declarou improcedentes os pedidos apresentados. Ademais, por meio da Resolução n.. 122-2001-JNE, de 5 de fevereiro de 2001, declarou inadmissíveis os pedidos de retificação formulados, considerando, entre outros, que a legislação eleitoral sobre as reservas de cotas para participação política não se refere exclusivamente ao gênero feminino, que não é discriminatória porque é uma regra que busca consolidar a igualdade jurídica entre os gêneros, e que a participação eleitoral é um direito das partes, cujo requisito essencial é o livre consentimento. 
Inconformado, o Defensor del Pueblo apresentou outros recursos perante os Jurados Electorales Especiales de cada um desses distritos eleitorais, como órgãos temporários responsáveis pela administração da justiça nesta matéria. O único Jurado Electoral Especial que respondeu foi o do distrito judicial de Ica, mediante resolução de 9 de fevereiro de 2001, que decidiu não aceitar o pedido, decisão atacada em recurso ao Jurado Nacional de Elecciones, que, por meio da Resolução n.․ 295-2001-JNE, de 4 de abril de 2001, declarou o recurso interposto improcedente, com os mesmos argumentos que haviam sido levantados por ocasião do pedido anterior feito diretamente pela Defensoría del Pueblo e pelas outras duas entidades mencionadas.

Destarte, as eleições gerais no Peru ocorreram em 8 de abril de 2001 sem respeitar, em três distritos eleitorais, os direitos das mulheres de participação política em condições de igualdade (VILLANUEVA FLORES, 2009, p. 299).

A petição apresentada perante a $\mathrm{CIDH}$ foi admitida por meio do Relatório n. ${ }^{51 / 02}$, pela alegada violação dos artigos 1.1, 23 e 24 da CADH.

O Estado peruano alegou falta de interesse para agir, pois, segundo alega, os peticionários não esgotaram todos os recursos previstos na legislação interna antes de recorrer às instâncias supranacionais. Aduziu que a cota é de gênero, portanto não se trata de uma ação afirmativa de participação política das mulheres.

Por fim, destaca que para o Jurado Nacional de Elecciones, há dificuldade em cumprir matematicamente o percentual de 30\% legalmente estabelecido no artigo 116 da Lei 27859, já que, segundo a distribuição de candidatos para cada distrito eleitoral indicado na Resolução n.․ 069-2001JNE, de 22 de janeiro de 2001, não seria possível determinar exatamente o número de assentos a serem concedidos das cotas mínimas para cada distrito eleitoral, procedendo então como uma solução para arredondar para o número mais próximo, como previsto no artigo 21 da Lei Orgânica de Eleições.

Os peticionários também assinalam que a verdade histórica no Peru, é que as listas para o Congresso sempre foram conformadas majoritariamente por homens, pelo que se trata de uma ação afirmativa da previsão legal das cotas.

Este caso, ainda não finalizado, caminha no mesmo sentido do caso María Merciadri vs. Argentina, já tendo havido, em 3 de janeiro de 
2003, manifestação da Defensoría del Pueblo e do Movimento Manuela Ramos expressando sua disposição para chegar a uma solução amistosa com o Estado peruano.

\section{Considerações finais}

O compromisso dos Estados com a democracia representativa, determinante no Sistema Interamericano, requer a aprovação de medidas que possibilitem a eleição de mulheres, o que inclui a adoção de um sistema eleitoral que favoreça a presença destas em postos de decisão sujeitos à eleição.

A análise dos casos acima apresentados revela que, indubitavelmente, os direitos políticos das mulheres estão abarcados pela força expansiva da proteção internacional dos direitos humanos, uma vez que tais direitos repousam solenemente em diversos tratados - globais e regionais - internacionais.

A violação dos direitos políticos das mulheres pelo Estado reclama, por conseguinte, o acionamento do sistema internacional de proteção dos direitos humanos, caso haja proteção deficiente no âmbito do direito doméstico.

Tanto a igualdade como a equidade são imperativos éticos, legais e sociais, que devem ser promovidos pelos Estados em todos os níveis de governo e instituições públicas. Enquanto houver desigualdade entre grupos de pessoas, não podemos pensar em ter uma sociedade mais justa (GUERREIRO AGUIRRE, 2014, p. 59). 


\section{Referências}

AMAYA, Jorge Alejandro. Los derechos políticos. 1. ed. Buenos Aires: Astrea, 2016.

BAREIRO, Line. Representación política de las mujeres. In: Tratado de derecho electoral comparado de América Latina / comps. Dieter Nohlen, Daniel Zovatto, Jesús Orozco, José Thompson. - 2. ed. - México: FCE, Instituto Interamericano de Derechos Humanos, Universidad de Heidelberg, International IDEA, Tribunal Electoral del Poder Judicial de la Federación, Instituto Federal Electoral, 2007, p. 679-692.

BRASIL. Constituição da República Federativa do Brasil de 1988. Disponível em: http://www.planalto.gov.br/ccivil_03/Constituicao/Constituicao.htm. Acesso em: 06 mar. 2019.

CEDAW. Observaciones finales del Comité para la Eliminación de la Discriminación contra la Mujer: Brasil, 2012, CEDAW/C/BRA/CO/7, 51 Periodo de Sesiones. New York: Naciones Unidas.

CEDAW. Observaciones finales del Comité para la Eliminación de la Discriminación contra la Mujer: Brasil, 2007, CEDAW/C/BRA/CO/6, 39. Período de Sesiones. New York: Naciones Unidas.

CEDAW. Observaciones finales del Comité para la Eliminación de la Discriminación contra la Mujer: Brasil, 2003, CEDAW/C/BRA/1-5, 29 Período de Sesiones. New York: Naciones Unidas.

COMISSÃO INTERAMERICANA DE DIREITOS HUMANOS. Consideraciones sobre la compatibilidad de las medidas de acción afirmativa concebidas para promover la participación política de la mujer con los principios de igualdad y no discriminación, 1999. Disponível em: http://www.cidh.oas.org/annualrep/99span/capitulo6a.htm. Acesso em: 27 fev. 2019.

COMISSÃO INTERAMERICANA DE DIREITOS HUMANOS. Informe n. 103/01. Caso 11.307. María Merciadri de Moroni vs. Argentina. 11 de octubre de 2001, IV. Solución amistosa, Acuerdo de solución amistosa.

COMISSÃO INTERAMERICANA DE DIREITOS HUMANOS. Informe n. 51/02. Petición 12.404. Janet Espinoza Feria y otras vs. Perú. 10 de octubre de 2002. 


\section{CORTE INTERAMERICANA DE DIREITOS HUMANOS. Caso}

Yatama vs. Nicarágua. Exceções Preliminares, Mérito, Reparações e Custas. Sentença de 23 de junho de 2005. Disponível em: http:/ /www.cnj.jus.br/ files/conteudo/arquivo/2016/04/b3b2dcefe29f27b2984178160015c3ba.pdf. Acesso em: 10 mar. 2019.

FERREIRA, Marcelo Ramos Peregrino. O controle de convencionalidade da lei da ficha limpa. Rio de Janeiro: Lumen Juris, 2015.

FLORES SALAZAR, Ana Lorena. Igualdad y derechos políticos de las mujeres. Medidas especiales de carácter temporal, paridad y políticas dinámicas y efectivas recomendadas por la CEDAW. Revista Derecho Electoral, San José, n. 22, 2016, p. 54-83.

GOMES, José Jairo. Direitos Políticos. Revista Brasileira de Estudos Políticos, Belo Horizonte, n. 100, p. 103-130, jan./jun. 2010.

GUERRERO AGUIRRE, Francisco Javier. Derechos políticos de la mujer. La igualdad en la participación política. In: Nuevas Avenidas de la democracia contemporânea. AYALA SÁNCHEZ, Alfonso (coord.). Universidad Nacional Autónoma de México, 2014, p. 48-59.

INTER-PARLIAMENTARY UNION. Women in National Parliaments: Situation as of 1 st January 2019. Disponível em: http:/ /archive.ipu. org/wmn-e/arc/classif010119.htm; http://archive.ipu.org/wmn-e/arc/ world010119.htm. Acesso em: 13 abr. 2019.

KROOK, Mona Lena; HUGHES, Melanie M.; PAXTON, Pamela. Gender quotas for legislatures and corporate boards. Annual Review of Sociology, 43, 331-352, 2017, p. 331-352.

MENDES, Gilmar Ferreira; BRANCO, Paulo Gustavo Gonet. Curso de direito constitucional. 7. ed. São Paulo: Saraiva, 2012.

MONTEIRO, Vítor de Andrade. Direitos humanos e direitos políticos: perspectivas e tendências do direito eleitoral perante o Sistema Interamericano de Direitos Humanos. Revista IIDH. San José, vol. 61, 2015, p. 173-200. PICADO, Sonia. Derechos políticos como derechos humanos. In: Tratado de derecho electoral comparado de América Latina / comps. Dieter Nohlen, Daniel Zovatto, Jesús Orozco, José Thompson. - 2. ed. — México: FCE, Instituto Interamericano de Derechos Humanos, Universidad de Heidelberg, International IDEA, Tribunal Electoral del Poder Judicial de la Federación, Instituto Federal Electoral, 2007, p. 48-59. 
VILLANUEVA FLORES, María de Rocío. La protección de los derechos políticos de las mujeres. In: Interpretación de los principios de igualdad y no discriminación para los derechos humanos de las mujeres en los instrumentos de los derechos humanos de las mujeres. San José. Instituto Interamericano de Derechos Humanos, 2009, p. 282-301.

Pedro Henrique Costa de Oliveira - Mestre em Direito, Políticas Públicas e Desenvolvimento Regional pelo Programa de Pós-Graduação em Direito do Centro Universitário do Estado do Pará (PPGD/CESUPA). Especialista em Direito Público pela Pontifícia Universidade Católica de Minas Gerais (PUC Minas) e em Direito Eleitoral pelo Instituto Brasiliense de Direito Público (IDP). Bacharel em Direito pelo CESUPA. Professor de Direito Eleitoral nos cursos de graduação em Direito da Faculdade Integrada Brasil Amazônia (FIBRA) e da Faculdade de Belém (FABEL), onde, nesta última, também integra o corpo docente da Pós-Graduação lato sensu em Direito Eleitoral. Presidente da Comissão de Direito Eleitoral da OAB/PA (gestão 2015-2018). Membro-fundador da Academia Brasileira de Direito Eleitoral e Político (ABRADEP). Advogado. 
